\title{
ESTUDO DE VIABILIDADE DA IMPLANTAÇÃO DE UM PONTO DE ENTREGA VOLUNTÁRIA (PEV) NA UNIVERSIDADE DO ESTADO DO PARÁ, CAMPUS VI: COLETA DE PILHAS E BATERIAS
}

\author{
Mário Marcos Moreira da Conceição ${ }^{1}$ \\ Marcelo Coelho Marques ${ }^{2}$ \\ Emmanuelle Rodrigues Pereira ${ }^{3}$ \\ Antônio Pereira Junior ${ }^{4}$
}

Resumo: A pesquisa teve como objetivo analisar as transformações no trato da relação entre a produção dos resíduos sólidos (especificamente pilhas e baterias), para viabilizar a implantação de Ponto de Coleta Voluntária na universidade do estado do Pará Campus VI. Os dados obtidos em relação a necessidade de existência da implantação de um coletor seletivo para pilhas e baterias no Campus VI - Paragominas, indicaram que, a maioria dos indivíduos amostrados $(95,6 \%)$ perceberam tal necessidade. Com isso, foi comprovada a viabilidade de implantação desse tipo de coletor seletivo e que o Campus VI pode ser um Ponto de Entrega Voluntário para pilhas e baterias para determinar uma mitigação quanto a disposição final desses geradores de energia.

Palavras-chave: Descarte, Resíduos, Sustentabilidade.

\footnotetext{
1 Universidade do Estado do Pará. E-mail: mariomarcoscm.7@gmail.com

2Universidade do Estado do Pará. E-mail: m.coelhomarques@gmail.com

${ }^{3}$ Centro de Estudos Superiores do Estado do Pará. E-mail: emmanuellepereira@gmail.com

4 Universidade do Estado do Pará. E-mail: antonio.junior@uepa.br
} 


\section{Introdução}

A disposição final dos resíduos sólidos, especialmente pilhas e baterias, é facilitada quando há, em postos estratégicos como, por exemplo, locais de grande circulação pública, receptores seletivos, ou ainda, pontos de entrega voluntária - PEV's, desses resíduos que, posteriormente, sejam devolvidos ao fabricante, para que se complete o ciclo da logística reversa.

No contexto histórico, a primeira pilha foi criada em 1800, por Alessandro Volta (1745-1827). As pesquisas e estudos realizados por Galvani (1737-1798) influenciaram Volta, que após mais estudos e pesquisas, desenvolveu um dispositivo formado por prata $(\mathrm{Ag})$ e zinco $(\mathrm{Zn})$ ou prata e chumbo $(\mathrm{Pb})$ ou prata e estanho $(\mathrm{Sn})$ ou por cobre $(\mathrm{Cu})$ e estanho (NOGUEIRA et al., 2011).

No final da década de 1970 surgiram os primeiros sinais de alerta sobre os perigos de se descartar baterias e pilhas usadas junto com o resíduo comum (KEMERICH et al., 2013). Estes resíduos, quando descartados inadequadamente, trazem grandes prejuízos ao meio ambiente por conter substâncias químicas e metais pesados que, em contato com a umidade, calor e outras substâncias, esses componentes tóxicos vazam e contaminam o solo, a água, as plantas e os animais (MORETTI; LIMA; CRNKOVIC, 2011).

Estudo acerca da implantação de um instrumento de coleta seletiva é de extrema importância e de grande relevância para o meio ambiente e a comunidade do entorno desse ponto de coleta, ou seja, local de entrega voluntária, pois, isso poderá determinar menor quantidade de resíduos depositados em locais inadequados e que são impactados (SOUZA, 2014). Tal fator é impulsionado pela demanda crescente de negligências quanto ao descarte de lixo por parte da população, aliada à falta de locais para alocação adequada de resíduos sólidos ou com alto índice de periculosidade como pilhas e baterias (BRASIL, 2010).

Porém, isso ainda não ocorre com mais eficácia porque a existência dos Pontos de Entrega Voluntário - PEV's, não abrange a maior parte dos municípios do país e se concentram na capital. Esta ferramenta tem o objetivo de coletar embalagens usadas ou resíduos perigosos e dar uma destinação ambientalmente adequada por meio da criação de redes logísticas em torno de fluxos reversos. Contudo, a preocupação interinstitucional dos geradores dos resíduos, do poder público e da legislação vigente nem sempre é convergente (GERBER; PASQUALI; BECHARA, 2015).

Quanto a viabilidade, ela é definida como a possibilidade de algo ser realizado. No que se refere à destinação e disposição final de resíduos, tal exequibilidade é impulsionada pela demanda crescente de negligências quanto ao descarte e falta de locais adequados para os resíduos como pilhas e baterias, produtos esses que, quando descartados no meio ambiente, trazem grandes prejuízos por conter substâncias químicas (OLIVEIRA; LIMA, 2016). Tal preocupação é porque estes produtos causam uma gama de impactos ambientais, dentre eles, está a poluição do solo, crescente no mundo, principalmente pelo depósito de materiais e rejeitos, como pilhas e baterias, 
que são materiais com alto índice de periculosidade, o que ocasiona eventuais mudanças na estrutura física desse solo (GAUDÊNCIO, 2015).

Esse entrave se origina do processo de obsolescência programada que acelera a produção de aparelhos em uma escala de tempo cada vez menor, pela substituição de obsoletas tecnologias por novas, o que gera mais resíduo. Dentre estes, estão àqueles advindos de aparelhos de comunicação móveis em desuso. Tais produtos possuem em sua composição, metais pesados causadores de problemas ambientais graves através da poluição de solos, águas, e do ar, se queimados emitem gases tóxicos, fator que também prejudica a qualidade de vida da população (KEMERICH et al., 2012; QUINTANA; BENETTI, 2016).

Em âmbito mundial, o Brasil está entre os primeiros países em termos de consumo de aparelhos móveis, atrás apenas da China, dos Estados Unidos e do Japão, motivo pelo qual, os fabricantes vêm tentando evoluir nas tecnologias para aumentar ainda mais o consumo, com isso há geração de mais resíduos e mais poluentes. Tal fato requer medidas que mitiguem ou minimizem a proporção de resíduos perigosos que ainda se dá de forma inadequada (CARVALHO; BARATA; ALVES, 2016; NEVES; SANTOS, 2015).

$O$ primeiro ponto de coleta piloto para telefones celulares ocorreu na Europa em 1997, e abrangeu seis indústrias presentes na Suécia e Reino Unido. Desde então, começaram a surgir iniciativas de coleta com o intuito de aumentar a preocupação do consumidor frente às necessidades e benefícios da reciclagem dos resíduos eletroeletrônicos. Um exemplo desse tipo de iniciativa é o ponto de coleta ou take-backkiosk criado pela Nokia no final de 2005 com o objetivo de incentivar a coleta de celulares. Em uma escala global, menos de $10 \%$ da população reciclou seu celular antigo, mesmo em países desenvolvidos como na Europa e nos Estados Unidos, onde a taxa de reciclagem de celulares antigos é de aproximadamente 15\%. A gerente de sustentabilidade da empresa evidenciou a necessidade de colocar pontos de coleta em locais de fácil acesso e seguro, e destacou a importância do consumidor para a eficiência e sucesso do projeto (TANSKANEN, 2013).

Com a evolução do sistema capitalista devido a tentativas das indústrias em potencializar seus lucros e satisfazer as necessidades dos consumidores, houve incremento entre a produção industrial de bens de consumo (Ex.: telefonia móvel) e a conservação do meio ambiente, porem as corporações tendem a não praticar a logística reversa e com isso ocorre um aumento no acúmulo dos resíduos provenientes de aparelhos eletro eletrônicos como pilhas e baterias descartados inadequadamente e agravado pelo intenso consumismo (ALMEIDA JÚNIOR; GOMES, 2012).

Com base nesses argumentos, justifica-se a realização dessa pesquisa, que tem como objetivo a análise qualitativa das transformações no trato da relação entre a produção dos resíduos sólidos (especificamente pilhas e baterias), e o recente sistema da logística reversa, para viabilizar a implantação de Ponto de Entrega Voluntária na Universidade do Estado do Pará Campus VI.

revista brasileira educação ambiental 


\section{Revisão da literatura}

\section{O descontrole e as transformações no trato dos resíduos sólidos}

$\mathrm{Na}$ segunda metade do século XX, o crescimento descontrolado das atividades produtivas do consumo desenfreado da população e a elevação na geração de resíduos sólidos levaram a uma veloz degradação de ambientes naturais, seja para a geração de recursos produtivos, seja pelo acúmulo de poluentes. Multiplicaram-se as pessoas afetadas por sérios problemas ambientais e, como consequência, emergiram robustos movimentos sociais questionando os fazeres e os saberes dos propositores do industrialismo. No entanto, desde o início houve vozes discordantes. Nos séculos XIX e XX, muito se debateu sobre a necessidade de conservação ou preservação de ambientes naturais. Neste contexto, compreendeu-se que certos bens naturais deveriam ser conservados, onde, para isso, é imprescindível a adoção de políticas neste sentido (MUIR, 2008; MCKIBBEN, 2008).

\section{Resíduos sólidos e perigosos}

Os Resíduos sólidos são materiais que geralmente perdem sua utilidade para a fonte geradora e podem ter a definição baseada em seu estado material, sendo divididos em sólidos, líquidos e gasosos. São também substâncias de origem orgânica e inorgânica, no estado sólido ou semissólido, tais como alimentos, cinzas ou restos de animais mortos, sobras de demolição e/ou construção, pesticidas, materiais contaminados, explosivos ou radioativos e outros resultantes de atividades industriais, comerciais, agrícolas e residenciais (KRIEGER et al., 2010).

Os resíduos perigosos são aqueles que, em razão de suas características de inflamabilidade, corrosividade, reatividade, toxicidade, patogenicidade, carcinogenicidade, teratogenicidade e mutagenicidade, apresentam significativo risco à saúde pública ou à qualidade ambiental. Os fabricantes, importadores, distribuidores e comerciantes de tais resíduos são obrigados a estruturar e implementar sistemas de logística reversa, mediante retorno dos produtos após o uso pelo consumidor, de forma independente do serviço público de limpeza urbana e de manejo dos resíduos sólidos (BRASIL, 2010).

\section{Pilhas e baterias}

A Resolução CONAMA n. 401: 2008, define as pilhas como geradores eletroquímicos de energia elétrica, mediante conversão de energia química, podendo ser do tipo primária (não recarregável) ou secundária (recarregável). São pequenos dispositivos capazes de gerar energia elétrica através de uma reação química. Para que isso ocorra, são necessários alguns componentes que atuem na reação química, e assim se consiga a liberação de energia. Isso em função do par de eletrodos metálicos diferentes, onde um deles é o polo positivo e o outro sendo o polo negativo. Tais materiais se depositados em locais inadequados podem causar prejuízos ao meio ambiente e a saúde dos 
organismos vivos, principalmente ao ser humano (QUINTANA; BENETTI, 2016).

As baterias são acumuladores recarregáveis ou conjuntos de pilhas, interligados em série ou em paralelo. Enquanto a pilha apenas converte energia química em elétrica, a bateria faz a interconversão entre energia química e elétrica. Ou seja, na pilha, quando seu potencial energético termina, ela não serve mais, enquanto que, nas baterias, elas podem ser recarregadas e utilizadas novamente por várias vezes. Todavia, a gestão desses resíduos, deve ser considerada prioridade por parte das empresas e da população, por apresentarem na composição química, elementos passíveis de danos ambientais (MORETTI; LIMA; CRNKOVIC, 2011).

\section{Composição química de pilhas e baterias}

As pilhas e as baterias são compostas basicamente por metais pesados, tais como mercúrio $(\mathrm{Hg})$, chumbo $(\mathrm{Pb})$, cobre $(\mathrm{Cu})$, níquel $(\mathrm{Ni})$, zinco $(\mathrm{Zn})$, cádmio (Cd) e lítio (Li). Esses metais são perigosos para o ambiente e a saúde humana. $O$ vazamento desses objetos pode contaminar solos e por extensão, 0 lençol freático, dependendo da concentração dessas substâncias pode causar câncer, doenças no sistema nervoso, rins entre outras. Tal fato também pode afetar negativamente os ecossistemas aquáticos além de serem incorporados nas cadeias alimentares, aumentando assim a sua concentração nos seres vivos (CARVALHO; BARATA; ALVES, 2016).

\section{Efeitos negativos a saúde humana e ao meio ambiente}

Os metais presentes nas pilhas e baterias são potencialmente perigosos à saúde humana e a qualidade ambiental (Quadro 1).

Quadro 1: Efeitos negativos dos metais pesados a saúde humana e qualidade ambiental.

\begin{tabular}{|l|l|l|}
\hline \multicolumn{1}{|c|}{ Metal } & \multicolumn{1}{|c|}{ Efeitos à saúde humana } & \multicolumn{1}{c|}{ Efeitos ao meio ambiente } \\
\hline $\begin{array}{l}\text { Cádmio } \\
(\mathrm{Cd})\end{array}$ & $\begin{array}{l}\text { Câncer, disfunção renal, disfunção } \\
\text { digestiva (náusea, vômito), problema } \\
\text { pulmonares. }\end{array}$ & $\begin{array}{l}\text { Apresenta um perigo potencial para o } \\
\text { meio ambiente devido a sua aguda e } \\
\text { crônica toxicidade e seus efeitos } \\
\text { cumulativos. }\end{array}$ \\
\hline $\begin{array}{l}\text { Mercúrio } \\
(\mathrm{Hg})\end{array}$ & $\begin{array}{l}\text { Dermatite, diarreia com sangramento, } \\
\text { dores abdominais, elevação da pressão } \\
\text { arterial, gengivite, dores de cabeça. }\end{array}$ & $\begin{array}{l}\text { Essa substância acumula-se em seres } \\
\text { vivos e se concentra através da cadeia } \\
\text { alimentar, particularmente via peixes e } \\
\text { mariscos. }\end{array}$ \\
\hline $\begin{array}{l}\text { Chumbo } \\
(\mathrm{Pb})\end{array}$ & $\begin{array}{l}\text { Anemia, disfunção renal, dores } \\
\text { abdominais (cólica, espasmo, rigidez), } \\
\text { Encefalopatia (sonolência, manias, } \\
\text { delírio, convulsões e coma). }\end{array}$ & $\begin{array}{l}\text { O chumbo se acumula no meio ambiente } \\
\text { e tem efeitos tóxicos agudos e crônicos } \\
\text { nas plantas, animais e microorganismos. }\end{array}$ \\
\hline $\begin{array}{l}\text { Manganês } \\
(\mathrm{Mn})\end{array}$ & $\begin{array}{l}\text { Disfunção do sistema neurológico, } \\
\text { gagueira e insônia. }\end{array}$ & $\begin{array}{l}\text { No meio ambiente tem maior exposição } \\
\text { organismos como algas, moluscos e } \\
\text { alguns peixes pela biomagnificação }\end{array}$ \\
\hline
\end{tabular}

Fonte: Autores (2017). 
Isso pode causar doenças crônicas e contaminação dos recursos naturais como a água e o solo, respectivamente. Tais metais, sendo bioacumulativos depositam-se no organismo, afetando suas funções orgânicas. Outras substâncias tóxicas presentes nesses produtos podem atingir e contaminar os aquíferos freáticos, comprometendo a qualidade desses meios (QUINTANA; BENETTI, 2016).

\section{Coleta seletiva}

A coleta seletiva é a primeira etapa do gerenciamento dos resíduos, que podem ser depositados em coletores com códigos de cores, onde, para os resíduos perigosos como pilhas e baterias, a cor é cinza. É também o Método de separação dos resíduos urbanos, industriais, hospitalares e laboratoriais com a classificação dos materiais para fins de reciclagem, realizada por catadores, órgãos públicos, empresas, entidades civis e cidadãos (KRIEGER et al., 2010).

Tal coleta reduz o volume de materiais destinado aos aterros sanitários ou lixões e proporciona economia de recursos naturais como petróleo, madeira, alumínio, ferro, aço, água e energia. Também é uma opção de renda pela comercialização dos materiais passíveis de reutilização ou reciclagem. No contexto deste processo é extremamente importante não esquecer que a responsabilidade legal pelos resíduos gerados é de quem os gera (SZABÓ, 2010).

\section{PNRS e a Logística Reversa}

A Lei n. 12.305:2010, institui a Política Nacional de Resíduos Sólidos PNRS, regulamentada pelo Decreto n. 7.404:2010 obriga aos fabricantes, praticarem a logística reversa, como instrumento de desenvolvimento social e econômico, no qual os produtores têm o dever de orientar seus consumidores sobre os riscos ambientais de seus produtos, de como deve ser 0 acondicionamento e a devolução dos bens após o consumo. Porém, isso de fato não ocorre, prejudicando o meio ambiente e consequentemente a qualidade de vida da população. Contudo para que ocorra de forma adequada vale ressaltar que é necessário que haja a educação ambiental para sensibilizar a população da importância do gerenciamento correto de tais resíduos (DEMAJOROVIC et al., 2012).

Tal lei, com a tentativa de minimizar os problemas dos resíduos, menciona a responsabilidade de produtores e consumidores que os mesmos são responsáveis pela destinação e o correto tratamento do material excedido através da logística reversa. Sendo assim, tal ferramenta consiste em atividades de coleta de materiais utilizados, danificados ou até mesmo rejeitados pelos fabricantes, importadores, distribuidores e vendedores instituindo a responsabilidade de uma destinação ambientalmente adequada, 
facilitando o retorno dos resíduos aos seus geradores (THODE FILHO et al., 2015).

Neste contexto, a PNRS obriga a estruturação e implementação de uma cadeia de logística reversa - LR, para os resíduos eletroeletrônicos. Assim, é apresentado 0 acordo consolidado entre os Governos, fabricantes, importadores, consumidores ou comerciantes a responsabilidade do ciclo de vida do produto, o que determina mecanismos de processos de formulação de políticas públicas relacionada a resíduos sólidos (NEVES; SANTOS, 2015).

Diante disso, os geradores têm a obrigatoriedade em relação ao retorno dos produtos, após o uso dos consumidores, de forma independente do serviço público de limpeza urbana e de manejo, além de estruturar e implementar sistemas de logística e auxiliar na prevenção do meio ambiente em relação aos impactos possíveis de forma a colaborar para o desenvolvimento social e econômico, tendo o valor corporativo adjunto. Dessa forma, a logística reversa torna possível tanto o desagravo aos impactos ambientais causados por produtos elétricos e eletrônicos, quanto 0 ganho de eficiência e sustentabilidade das operações nas organizações (LAVEZ; SOUZA; LEITE, 2011).

Outro fator que potencializa esta ferramenta ambiental, é o princípio da responsabilidade ampliada do produtor (Extended Porducer Responsability), onde as empresas produtoras deverão realizar o recolhimento, a reciclagem e a destinação ambientalmente correta de certos resíduos. A nova lei amplia não apenas 0 encargo do produtor, como também a responsabilidade do consumidor, pois ele deve acondicionar de forma adequada o resíduo para posterior recolhimento. Com esta ampliação da logística reversa, o produtor tem que assumir os custos com a captação e destinação ambientalmente correta dos resíduos gerados pelos seus produtos. Esta responsabilidade implica que o fabricante é responsável por todos os danos causados pelo produto durante o seu ciclo de vida (HERDIANA et al., 2014).

\section{Legislação sobre pilhas e baterias}

\section{Conselho Nacional de Meio Ambiente (CONAMA)}

A bateria presente nos celulares e outros aparelhos eletroeletrônicos possui parcela significativa de substâncias químicas nocivas ao meio ambiente e aos seres humanos tendo como um dos principais, o chumbo, cádmio e mercúrio. Baseada nessa vertente foi promulgada a Resolução CONAMA, $n$. 401:2008, art. 1, que estabelece os limites máximos desses elementos químicos para pilhas e baterias comercializadas no território nacional e os critérios e padrões para o seu gerenciamento ambientalmente adequado, e dá outras providências de modo a minimizar os impactos gerados por tais resíduos (BRASIL, 2008).

São estabelecidos pela Resolução CONAMA, n. 257:1999, que, as pilhas e baterias que contenham em suas composições chumbo, cádmio, 
mercúrio e seus compostos, necessárias ao funcionamento de quaisquer tipos de aparelhos, veículos ou sistemas móveis ou fixos, bem como os produtos eletroeletrônicos que as contenham integradas em sua estrutura de forma não substituível, após seu esgotamento energético, serão entregues pelos usuários aos estabelecimentos que as comercializam ou à rede de assistência técnica autorizada pelas respectivas indústrias para repasse aos fabricantes ou importadores, para que estes adotem, diretamente ou por meio de terceiros, os procedimentos de reutilização, reciclagem, tratamento ou disposição final ambientalmente adequada (BRASIL, 1999).

\section{Política Nacional de Resíduos Sólidos - PNRS}

A PNRS instrui para a prevenção e a redução na geração de resíduos, prática de hábitos de consumo sustentável e um conjunto de instrumentos para propiciar o aumento da reciclagem e reutilização dos resíduos e a destinação ambientalmente adequada dos rejeitos. Ela também institui a responsabilidade compartilhada dos geradores de resíduos: dos fabricantes, importadores, distribuidores, comerciantes, o cidadão e titulares de serviço de manejo dos resíduos sólidos urbanos na Logística Reversa dos resíduos e embalagens pós-consumo (BRASIL, 2010).

A referida lei objetiva reduzir o volume e a periculosidade de resíduos sólidos, prioriza a não geração, a redução, a reutilização, a reciclagem, o tratamento dos resíduos sólidos e disposição final ambientalmente adequada dos rejeitos. Além de abordar princípios, finalidades, ferramentas e diretrizes adotadas pelo Governo Federal, independente de regime de cooperação dos estados, Distritos Federais, municípios ou particulares com vistas a gestão integrada de gerenciamento adequado dos resíduos sólidos está acompanhada de instrumentos inovadores, como a responsabilidade compartilhada e a determinação de contemplar a inclusão social dos catadores (GINDRI; LHAMBY, 2016).

\section{Educação Ambiental}

A Lei n. 9.795:1999 que instituiu a Política Nacional de Educação Ambiental - PNEA, regulamentada pelo Decreto n. 4.281: 2002, é voltada para uma sensibilização sobre a Qualidade Ambiental - QA, pois surge como uma ferramenta para o desenvolvimento sustentável com objetivo de não apenas instruir, mas também incluir mudanças de valores, hábitos e atitudes dos cidadãos. As práticas sustentáveis devem funcionar, e que alcançar os seus objetivos, de tal forma que uma sociedade educada ambientalmente possua um caráter crítico, inserida como uma educação interdisciplinar de saberes e atitudes, envolvendo a participação do indivíduo na conscientização de novos métodos sustentáveis (SOUZA, 2014).

Com a falta de sensibilização da população em relação a alocação adequada de resíduos sólidos e o crescente consumo de itens eletrônicos, 
houve o aumento considerado do descarte indevido de pilhas e baterias, no qual ocasiona a poluição do solo e lençol freático. Portanto, a criação de políticas internas nas instituições públicas e privadas, como campanhas educativas, tem a importância de sensibilizar consumidores para a necessidade do descarte adequado destes materiais perigosos, o que evita danos ao meio ambiente e a saúde humana de forma sustentável e promissora quanto à qualidade socioambiental (OLIVEIRA et al., 2013).

\section{Fisiografia do município e área de estudo}

A pesquisa foi realizada no município de Paragominas (Figura 1), situado no nordeste do Pará, o qual possui como principal via de comunicação e transporte a Rodovia Belém - Brasília (BR-010), distante à $320 \mathrm{~km}$ da região metropolitana de Belém, apresentando as coordenadas: latitude $02^{\circ} 59^{\prime} 4^{\prime \prime} \mathrm{S}$, longitude $47^{\circ} 21^{\prime} 10^{\prime \prime} \mathrm{W}$, altitude de 90 metros e uma área aproximada de $19.342,254 \mathrm{~km}^{2}$, e com densidade demográfica de 5,06 habitantes por $\mathrm{km}^{2}$, e uma população estimada em 108.547 habitantes (IBGE, 2016).

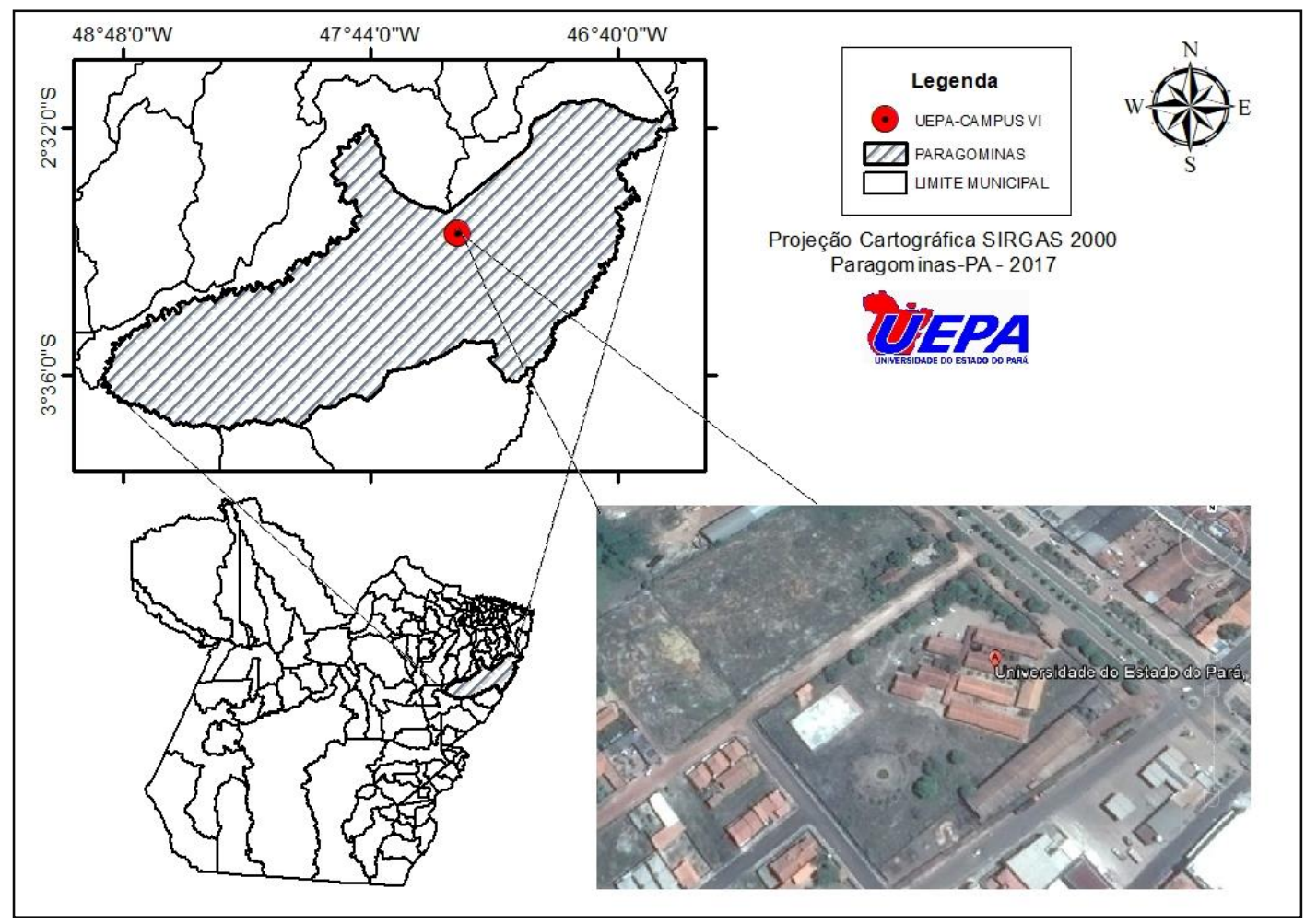

Figura 1: Mapa de localização da área de estudo, Paragominas - PA.

Fonte: Autores (2017)

O estudo foi realizado no Campus da Universidade Estado do Pará, na cidade de Paragominas, e possui as seguintes coordenadas: S $02^{\circ} 59^{\prime} 07,6^{\prime \prime} \mathrm{e}$ W $47^{\circ} 21^{\prime} 30,9^{\prime \prime}$ e elevação de 87 metros. Situado na Rodovia PA-125, no Bairro Angelim o Campus VI foi fundado em 1993, e oferta, na atualidade, os 
seguintes cursos presenciais: Engenharia Florestal, Engenharia Ambiental, Design, Biologia; modalidade à distância: Biologia e Pedagogia; Plano Nacional de Formação de Professores - PARFOR e Educação Física.

\section{Clima, vegetação, solo e hidrologia do município}

Paragominas possui clima quente e úmido, com temperatura média anual de $26,3^{\circ} \mathrm{C}$ e umidade relativa do ar elevada, com média anual em torno de $80 \%$ e médias mensais variando de $70 \%$ a $90 \%$. A precipitação pluviométrica, elemento meteorológico de maior variabilidade climática, cujos valores pluviométricos anuais variam de $857,8 \mathrm{~mm}$ a $2.787,7 \mathrm{~mm}$, com média anual de $1.800 \mathrm{~mm}$ (PINTO et al., 2009).

A vegetação original da região era composta principalmente por florestas tropicais densas de terra firme e perenes, entretanto, devido o avanço da supressão vegetal da região oriundo da atividade de agropecuária, grandes áreas de floresta nativa foram substituídas por florestas secundárias (capoeira nos seus diversos estágios de desenvolvimento. $\mathrm{O}$ tipo de solo predominante no município é o latossolo amarelo distrófico, que cobre $95 \%$ da sua área. Quanto à hidrografia, há duas bacias principais: a do rio Capim, cujos tributários se ramificam por $54 \%$ da área do município, e a do rio Gurupi que ocupa os $46 \%$ restantes. Mais de $70 \%$ da área do município se encontra entre 50 e 150 metros acima do nível do mar (PARÁ, 2008).

\section{Metodologia da pesquisa}

O método empregado foi o hipotético-dedutivo, associada a pesquisaação exploratória, observativa, sistemática, direta. Em relação à abordagem, empregou-se a qualiquantitativa, onde os métodos qualitativos buscam explicar o porquê das coisas e sua origem, relações e mudanças, e tenta intuir as consequências, de forma a adquirir uma compreensão detalhada dos significados e características situacionais apresentados pelos entrevistados (OLIVEIRA, 2011).

Já o quantitativo tem as raízes no pensamento positivista lógico, enfatiza o raciocínio dedutivo, a lógica com suas regras e os atributos mensuráveis da experiência antrópica (GERHARDT; SILVEIRA, 2009). Essa metodologia foi complementada com o levantamento de dados documentais em sites de busca aberta (Google Scholar, Ler livros, ISSUU, WebScience) e em instituições envolvidas a pesquisa ambiental (MMA; IBAMA; CONAMA).

Para a obtenção de dados, foram aplicados noventa e um formulários, em uma amostragem probabilística aleatória simples, de $20 \%$ da população acadêmica do Campus VI - Paragominas que é constituída de quatrocentos e cinquenta e dois acadêmicos distribuídos em quatro cursos ofertados, em três turnos (matutino, vespertino e noturno). Os formulários foram compostos por questões mistas (abertas e fechadas) acerca do conhecimento (beliesfs) dos discentes sobre as pilhas e baterias, quanto: (1) a composição química; (2) aos Revbea, São Paulo, V. 13, № 2: 351-371, 2018. 
possíveis danos causados ao homem e ao meio ambiente; (3) a forma que lidam com o descarte de resíduos dos eletros eletrônicos; (4) a necessidade de implantação de um sistema de gestão e gerenciamento de resíduos sólidos perigosos no Campus $\mathrm{VI}$, que promova um melhor engajamento de tal setor bem como a viabilidade da existência de mecanismos para essa integração, como, por exemplo, um ponto de entrega voluntária - PEV, no Município de Paragominas.

Após a coleta dos dados obtidos, estes foram tratados estatisticamente com o uso do software Excel, versão 15.0 e do software Origin 8.5. A estatística utilizada foi a descritiva (frequência absoluta - fi; frequência relativa fr); média aritmética - $\bar{X}$, desvio padrão - S; coeficiente de variação - CV).

Para o cálculo da frequência absoluta e relativa foram utilizadas as Equações 1 e 2 .

$f i=\sum n$

Onde:

$$
\begin{aligned}
& f i=i \text { frequência absoluta } \\
& \sum n=\text { somaria das frequências das amostras } \\
& f r=\frac{F i}{\sum F i}
\end{aligned}
$$

Onde:

$$
\begin{aligned}
& f i=i \text { frequência absoluta } \\
& \sum f i=\text { somaria das frequências absolutas }
\end{aligned}
$$

\section{Resultados e discussão}

Os dados obtidos para amostragem com os quatro cursos ofertados, indicou que o número de discentes amostrados por curso, efetivou-se de acordo com a presença dos mesmos quando da realização dessa pesquisa (Figura 2, próxima página).

$\mathrm{Na}$ pesquisa realizada em João Pessoa - PB, por Souza (2014) os dados indicaram que as Instituições de Ensino Superior - IES, tem uma responsabilidade social de disseminar o conhecimento e a informação para a sociedade agindo assim como um agente modificador. No Campus VI, há quatrocentos e cinquenta e dois acadêmicos, com isso, torna-se mais fácil promover a disseminação acerca das ocorrências negativas quanto a desinformação sobre pilhas e baterias. 


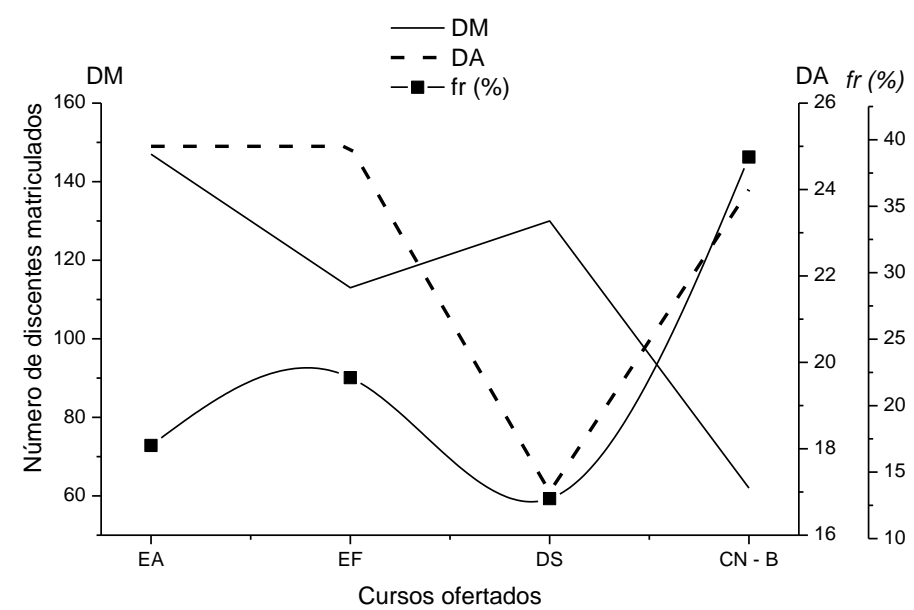

Legendas: DM: discentes matriculados; DA: discentes amostrados; Fr: Frequência Relativa; EA -Engenharia Ambiental; EF - Engenharia Florestal; DS - Designe; CN-B - Ciências Naturais Biologia.

Figura 2: Cursos ofertados, número de discentes matriculados, amostrados e os valores obtidos para a frequência relativa. Paragominas - PA. Fonte: Autores (2017)

Quanto ao tipo de aparelhos portáteis/não, os dados obtidos indicaram que $100 \%$ dos indivíduos amostrados, utilizam algum tipo de aparelho móvel (Figura 3).

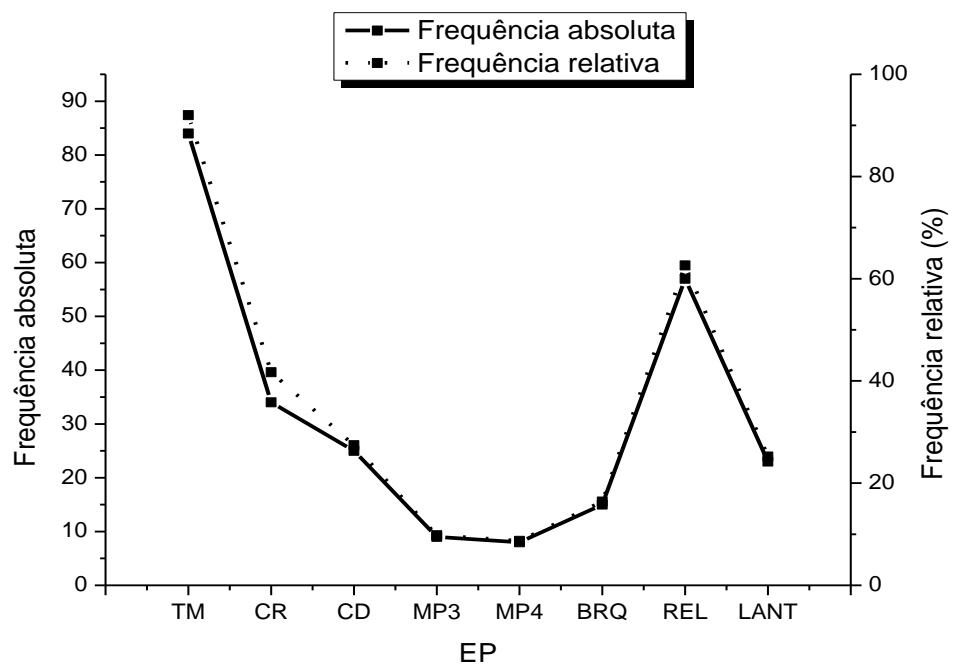

Legendas: TM: telefonia móvel; CR - Controle Remoto; CD - Câmera Digital; BRQ: Brinquedos; REL: Relógios; LANT: Lanternas. EP - Eletroeletrônicos Pesquisados.

Figura 3: Aparelhos eletro portáteis utilizados com mais frequência pelos indivíduos amostrados. Paragominas - PA. Fonte: Autores (2017)

A análise dos dados obtidos indicou que o uso de telefones móveis apresentou maior valor de frequência relativa (92,9\%). Isso está relacionado com a tendência moderna quanto a praticidade e manutenção da comunicação a distância ofertada por esse tipo de aparelho. Além de outros aplicativos (Ex.:

Revbea, São Paulo, V. 13, № 2: 351-371, 2018. 
Facebook, Calculadora cientifica/normal, Google, Global Positioning System GPS, rádio, relógio, cronômetro, etc.). Todavia, em pesquisa bibliográfica realizada por Nogueira et al. (2011), sobre descarte correto de pilhas e baterias, os autores concluiram que dois elas apresentam dois problemas: (1) compostos químicos, íon Lítio (Li); Níquel - Cádmio (Ni-Cd); Hidreto metálico de Níquel; Chumbo (Pb); retardantes de chamas de Bromados, cromo hexavalentes ( $\mathrm{Cr}(\mathrm{VI})$, Arsênio (As), Antimônio (Sb); (2) impactos causados (Quadro 2).

Quadro 2: Principais impactos causados pelos metais das baterias de telefones móveis.

Paragominas - PA.

\begin{tabular}{|c|c|c|}
\hline EQ & SQ & O que causa \\
\hline Lítio & Li & Inflamável; explosivo. \\
\hline Cádmio & $\mathrm{Cd}$ & $\begin{array}{c}\text { Provoca câncer; problemas pulmonares; } \\
\text { envenenamento. }\end{array}$ \\
\hline Níquel & $\mathrm{Ni}$ & $\begin{array}{c}\text { Provoca câncer; lesões no sistema } \\
\text { respiratório; altera o sistema imunológico. }\end{array}$ \\
\hline
\end{tabular}

Legendas: EQ - Elemento Químico; Símbolo Químico.

Fonte: Autores (2017)

No estudo efetuado em São Gabriel - RS, por Carvalho, Barata e Alves (2016), os autores concluíram que tais elementos químicos podem causar doenças crônicas como câncer, doenças no sistema nervoso, rins entre outras. Tais metais, sendo bioacumulativos depositam-se no organismo, o que afeta as funções orgânicas. Em relação a isso, a pesquisa realizada em Paragominas, comprovou que o descarte desse tipo de elemento é feito no meio, o que compromete a saúde da comunidade local, em face dos resultados obtidos em São Gabriel.

Os dados obtidos quanto ao modo de geração de energia dos aparelhos utilizados pelos indivíduos amostrados, indicaram que a quantidade e tamanho das fontes de energia utilizadas dos eletro-portáteis, apresentam-se de formas diferentes (Tabela 1).

Tabela 1: Dados sobre a quantidade, modelo e tamanho dos geradores de energia usados pelos discentes amostrados. Paragominas-PA.

\begin{tabular}{lllllllllllll}
\hline \multicolumn{10}{c}{ Quantidades Utilizadas } \\
\hline GE & OU & QA & & & T & & & M & & D & R \\
\hline & & $\mathbf{1}$ & $\mathbf{2}$ & $\mathbf{3}$ & $\mathbf{4}$ & P & M & G & 3A & 2A & - & - \\
$\mathrm{P}$ & 12 & 43 & 42 & 06 & 04 & 76 & 57 & 00 & 40 & 57 & 38 & - \\
$\mathrm{B}$ & 51 & - & - & - & - & - & - & - & - & - & - & 84 \\
$\mathrm{P}+\mathrm{B}$ & 37 & - & - & - & - & - & - & - & - & - & - & - \\
$\mathbf{f i}$ & $\mathbf{1 0 0}$ & $\mathbf{4 3}$ & $\mathbf{4 2}$ & $\mathbf{0 6}$ & $\mathbf{0 4}$ & $\mathbf{7 6}$ & $\mathbf{5 7}$ & $\mathbf{0 0}$ & $\mathbf{4 0}$ & $\mathbf{5 7}$ & $\mathbf{3 8}$ & $\mathbf{8 4}$
\end{tabular}

LEGENDAS: GE: Gerador de Energia; OU: Opção de Uso; QA: Quantidade de pilhas utilizadas por aparelho (1, 2, 3 e/ou 4); T: Tamanho; P: Pilhas; B: Baterias; P+B: Pilhas mais Baterias;

TG: Total Geral; M: Modelo; D: Descartável; R: Recarregável; P - Pequena; M - Média; G Grande; $3 \mathrm{~A}$ e $2 \mathrm{~A}$ - voltagem.

Fonte: Autores (2017). 
A análise desses dados indicou que a bateria é a unidade de geração de energia mais utilizada pelos indivíduos amostrados ( $f r=92,9 \%$ ), especialmente em telefonias móveis. Esse fator é impulsionado pela atualização constante desses aparelhos. A pesquisa realizada no município de Frederico Westphalen - RS, por Kemerich et al. (2013), indicou que tal entrave é advindo do processo de obsolescência programada que acelera a produção de novos produtos em uma escala de tempo cada vez menor, pela substituição de antiquadas tecnologias por novas, o que induz ao consumo de mais produtos que utilizam como fonte de energia, pilhas/baterias.

Os dados obtidos em relação ao local de descarte dos resíduos, indicou que esses locais oscilam entre coletores residuais comuns/seletivos, ou ainda, onde convier (Figura 4)

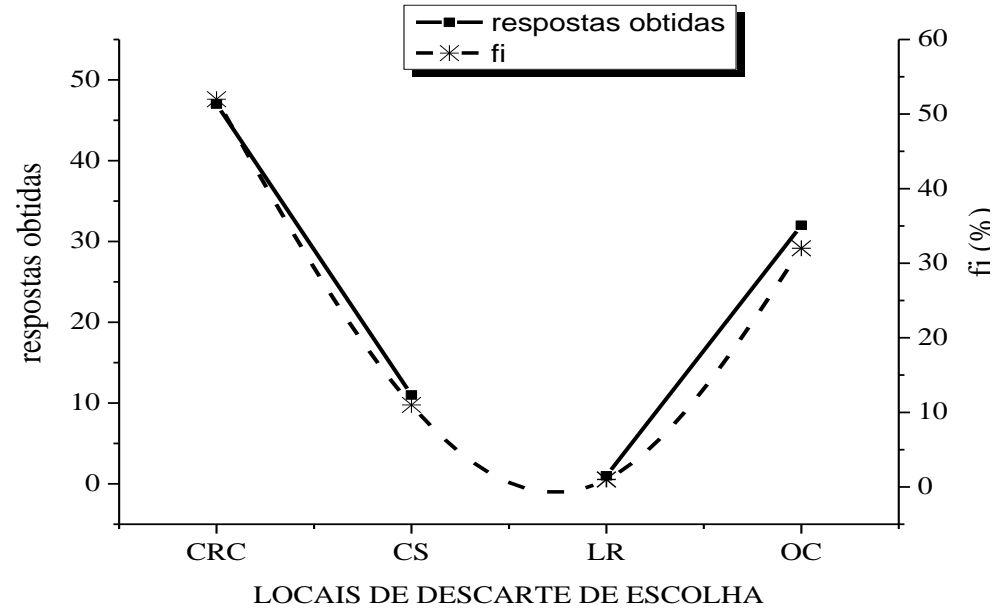

Legendas: CRC: Coletor Residual Comum; CS: Coletor Seletivo; LR: Logística Reversa; OC: Onde convier.

Figura 4: Locais de descartes dos resíduos sólidos. Paragominas - PA.

Fonte: Autores (2017).

O coletor residual comum (52\%) foi o mais citado pelos indivíduos amostrados, outra citação de destaque chamou a atenção: "onde convier" (35\%). Isso reflete que a percepção ambiental desses discentes ainda está ínfima, ou ainda, pode ser uma resposta quanto à falta de um local adequado para o descarte desses resíduos, que compromete a conservação do meio ambiente, pois, os compostos químicos geradores de energia, são reativos com a água do solo, e retira deste, o serviço ecossistêmico de extrema importância: a provisão, ou seja, compromete a fertilidade e a produção de cultivos agrícolas.

Estudo efetuado em São Gabriel - RS, por Quintana e Benetti (2016), concluiu que o descarte desses resíduos pode contaminar os recursos naturais como a água e o solo respectivamente. Tal fato de acordo com estudo efetuado em Mossoró - RN, por Gaudêncio (2015), esse autor concluiu que os metais que compõe as pilhas e baterias, são bioacumulativos, depositam-se no organismo, afeta as funções orgânicas, além de atingir e contaminar os recursos hídricos. 
Mas, o que chamou a atenção nos dados obtidos, foi a baixa tendência (1\%) quanto à prática da logística reversa. Associa-se a isso, o fato da ausência no município de Paragominas de locais para prática dessa logística, ou seja, não há Ponto de Entrega Voluntária - PEV, e isso induz o consumidor de pilhas e baterias a descarta-las, após o ciclo de vida útil, em locais inadequados e, consequentemente, incrementa a poluição ambiental.

Nas pesquisas realizadas em Capão Redondo - SP, por Oliveira e Lima (2016), e Neves e Santos (2015), sobre o descarte de aparelhos celulares em duas empresas, foi indicado que tal entrave é impulsionado pela demanda crescente de negligências quanto ao descarte de lixo por parte da população, aliada à falta de locais para alocação adequada de resíduos como pilhas e baterias, produtos esses que, quando descartados no meio ambiente, trazem grandes prejuízos por conter substâncias químicas.

Em analogia a isso, a pesquisa realizada em Paragominas Campus VI, comprovou que a maioria dos discentes não tem sensibilização referente ao descarte de pilhas e baterias, o que agrava os problemas quanto ao descarte de resíduos sólidos, em face dos resultados obtidos em Capão Redondo.

A partir da análise dos dados obtidos quanto à concepção da forma como os indivíduos amostrados realizam o descarte pilhas e baterias usadas, obteve-se duas tendências: adequada (8,7\%) e inadequada (91,3\%). É notório que há um desconhecimento acerca dos impactos ambientais e descomprometimento da indústria de bens de consumo não duráveis, em orientar os consumidores quanto à disposição final do produto pós-uso, mesmo assim, as empresas continuam a apregoar o chamado green marketing com o slogan: empresa ambientalmente correta para melhoria da imagem junto ao consumidor.

No estudo efetuado em São Paulo - SP, por Almeida Júnior e Gomes (2012), os autores concluíram que, além da utilização das questões ambientais para promoção de imagem pública, existem muitas evidências que apontam também para um aprendizado das empresas na utilização destas questões como um diferencial competitivo. Como se percebe, os dados obtidos em Paragominas indicam que as empresas não possuem uma imagem pública, a partir da confiabilidade na relação indústria-consumidor, resultante do aprendizado para a obtenção da titulação "ambientalmente correta".

Em relação ao conhecimento dos discentes quanto a existência de ponto de coleta seletiva de pilhas e baterias na cidade de Paragominas-PA, a análise dos dados obtidos indicou que a desinformação sobre isso, é predominante (Figura 5). 


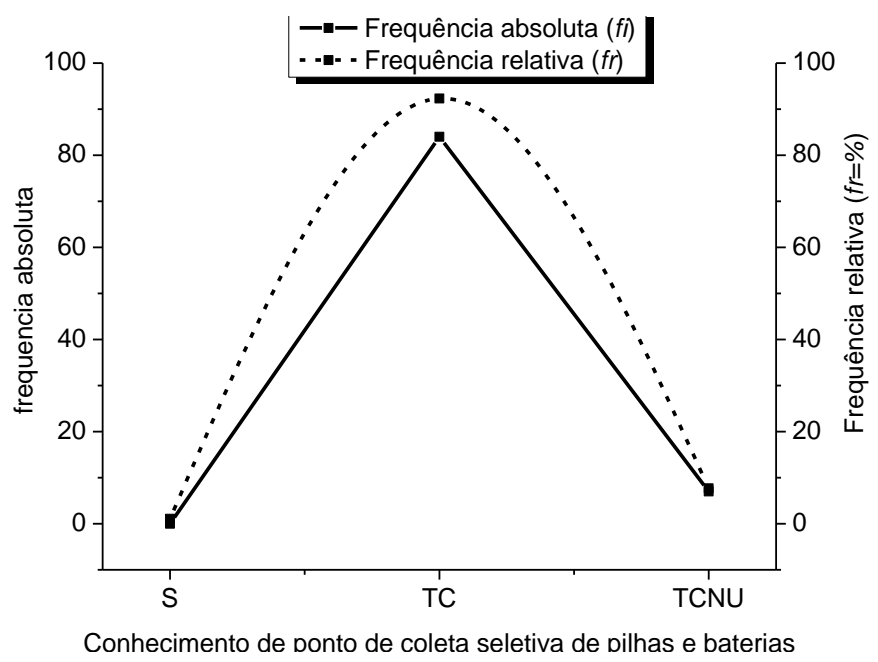

Legendas: S: Sim, sabe da existência da coleta seletiva para pilhas e baterias; TC: Tem conhecimento da não existência de tal ponto de coleta; TCNU: Tem conhecimento, mas não usa.

Figura 5: conhecimento dos discentes sobre a existência de um ponto de coleta de resíduos de eletroeletrônicos no município de Paragominas-PA. Fonte: Autores (2017)

Após a análise, verificou-se que uma minoria dos indivíduos amostrados (1\%) informaram conhecer a existência dos pontos de coletas seletivas no município de Paragominas - PA. Em contrapartida, 92,3\% afirmaram que tal ponto não existe e, finalmente, $6,7 \%$ tem conhecimento, mas não fazem uso desse ponto. A partir desses dados é possível concluir que a maior amostragem dos discentes sobre a existência do sistema de coleta seletiva do município, é condizente com a realidade, pois não existe um ponto coletor residual voluntário de resíduos eletroeletrônicos no município.

Em pesquisa realizada no estado de São Paulo - SP, por Moretti, Lima e Crnkovic (2011), a sociedade deve estar ciente dos locais possíveis de destinação desses produtos, além disso, a gestão desses resíduos deve ser considerada prioridade por parte das empresas e da população, por apresentarem na composição química, elementos passíveis de danos ambientais, e a saúde da sociedade. Além disso, no estudo realizado por Gerber, Pasquali e Bechara (2015) no Brasil, os autores afirmam que a preocupação interinstitucional dos geradores dos resíduos, do poder público e da legislação vigente deve ser de forma assídua.

Entretanto, o estudo efetuado no Campus VI, demonstra a assimetria entre o esforço para o consumo desses aparelhos e o pouco esforço em relação a percepção ambiental, pois os indivíduos amostrados, mesmo sem ter conhecimento sobre pontos de coletas de resíduos perigosos, aderem a prática do descarte inadequado.

Os dados obtidos sobre as três questões inerentes: (1) à destinação correta, (2) malefícios causados ao meio ambiente, e (3) a composição química de pilhas e baterias indicaram contradições sobre o conhecimento dos temas indagados aos discentes (Tabela 2).

Revbea, São Paulo, V. 13, № 2: 351-371, 2018. 
Tabela 2: Relação quantitativa da amostragem sobre a destinação correta, os malefícios e a composição química das Pilhas e Baterias. Paragominas - PA.

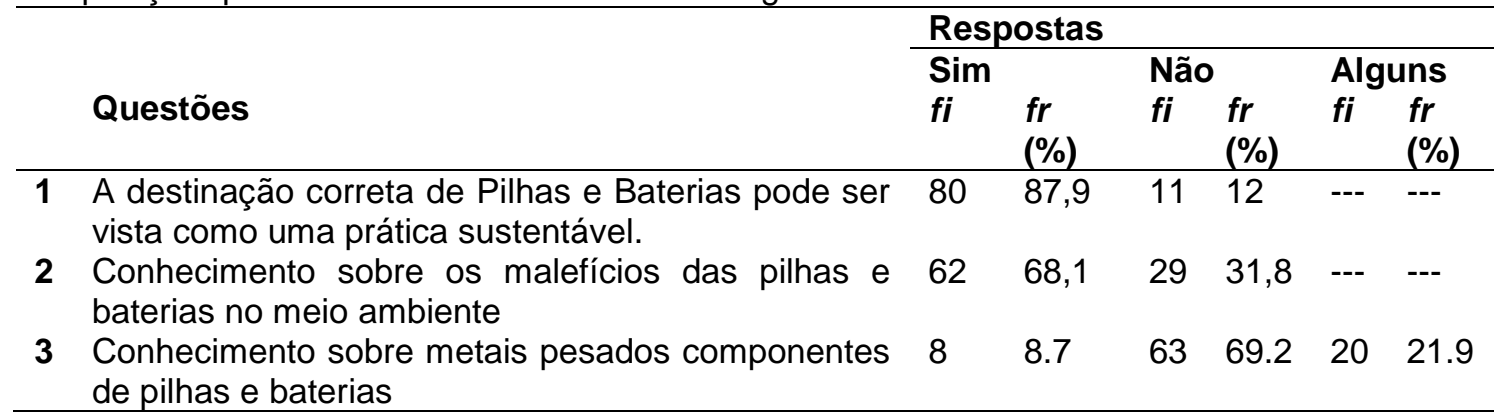

Fonte: Autores (2017)

A análise dos dados indicou que, dentre os indivíduos amostrados, há conhecimento acerca da prática sustentável (87,9\%) como consequência do descarte correto de pilhas e baterias, bem como os malefícios ambientais causados pelo descarte inadequado $(68,1 \%)$. Mas, o desconhecimento da composição química desses geradores de energia $(69,2 \%)$, não condiz com o conhecimento dos malefícios causados ao meio ambiente, pois a maior frequência da amostragem afirma não conhecer a composição química desses objetos e afirmam saber os danos causados ao meio ambiente.

Na pesquisa realizada em São Gabriel - RS, por Carvalho, Barata e Alves (2016), sobre a logística reversa de lixo eletrônico nas organizações públicas, verificou-se a necessidade de intensificação da divulgação e incentivo para a adoção da logística reversa, tanto por fabricantes, como por agentes governamentais, como também na divulgação da composição química de pilhas e baterias e dos malefícios oriundos do descarte inadequado desses materiais. Isso ajudaria na sensibilização da população e da comunidade acadêmica, para a questão da destinação correta destes resíduos.

Quanto à presença de metais pesados na composição de pilhas e baterias, a análise dos dados obtidos indicou que, apesar de terem conhecimento, os indivíduos amostrados $(20,1 \%)$, realizam o descarte incorreto desses objetos. No estudo efetuado em São Gabriel - RS, por Quintana e Benetti (2016), os autores concluíram que tais materiais, se depositados em locais inadequados, podem causar prejuízos ao meio ambiente e a saúde dos organismos vivos, principalmente ao ser humano, por alterar negativamente os recursos naturais como a água e o solo. Dessa forma, é imprescindível uma ação efetiva de logística reversa por parte da comunidade que ainda deposita seus resíduos de forma inconsequente, em locais inadequados como, por exemplo, vias urbanas. Em função disso, o ponto de entrega voluntária - PEV é uma estratégia para mitigar tal problema.

Outra solução é a incrementação da sensibilidade ambiental à comunidade acadêmica, com a realização de palestras, workshop, reuniões periódicas para a discussão dessa problemática, ou seja, envolver o ator 
ambiental quanto à manutenção da qualidade do meio ambiente e vida dos usuários desse meio.

Os dados obtidos em relação a necessidade de existência da implantação de um coletor seletivo para pilhas e baterias no Campus VI, indicaram que, uma grande maioria dos indivíduos amostrados (95,6\%) percebem a necessidade dessa implantação (Figura 6).

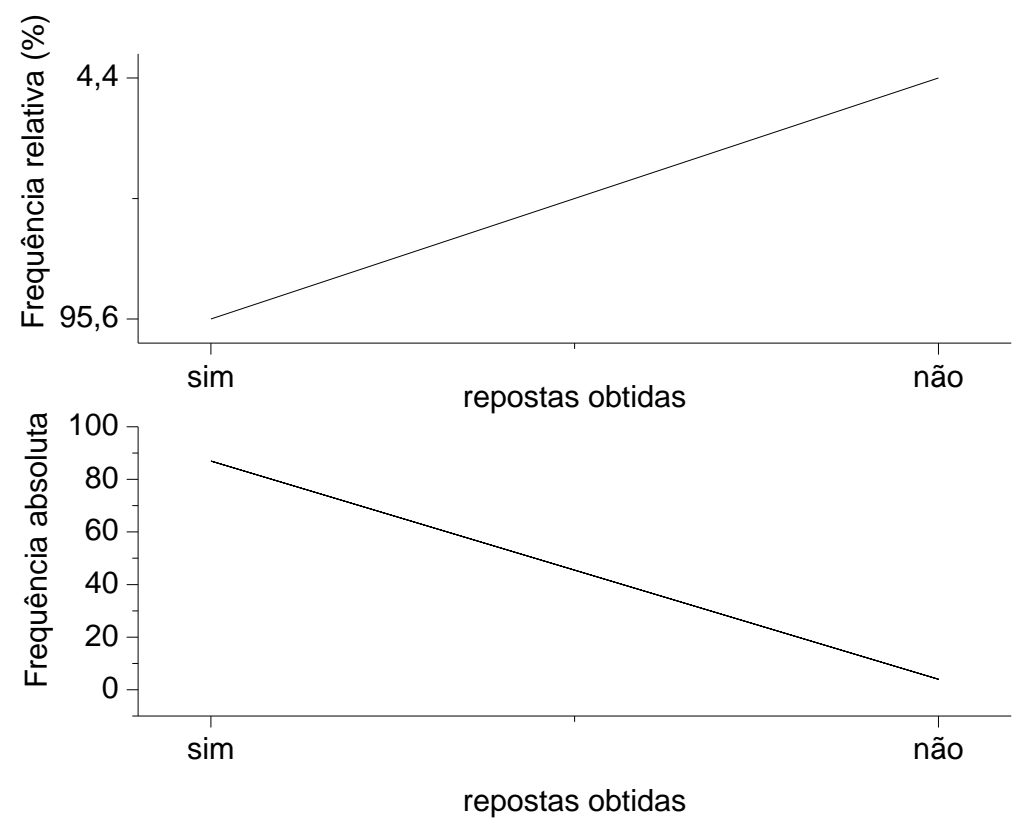

Figura 6: Dados obtidos quanto a amostragem sobre a implantação de um coletor residual no Campus VI, Paragominas-PA. Fonte: Autores (2017) .

Após a análise desses dados, foi perceptível que a implantação desse coletor seletivo irá permitir uma adequação para pilhas e baterias, além de contribuir para uma mitigação na agressão ambiental provocada pelos componentes químicos oriundo da decomposição desses geradores de energia em contato com o solo e sob a ação de variáveis ambientais como, por exemplo, elevação da temperatura do ar atmosférico. Pesquisa realizada em Capão Redondo - SP, por Oliveira e Lima (2016), sobre logística reversa na capital paulista indica que tal ferramenta é capaz promover o desenvolvimento sustentável. Além disso, Tanskanen (2013), em pesquisa sobre resíduos eletrônicos na Finlândia afirma que a gestão integrada de gerenciamento adequado desses resíduos sólidos fica interligada com instrumentos inovadores, como a responsabilidade da comunidade e dos fabricantes no processo de desenvolvimento socioambiental. 


\section{Conclusões}

A análise da transformação no trato da relação entre a produção de resíduos, em especial, pilhas e baterias, cujo ciclo de vida é limitado por horas, e pode ser melhorada a partir da implantação de Ponto de Entrega voluntária. O sistema da logística reversa ainda não está implantado no município de Paragominas, e isso é um incentivo ao descarte irregular dos geradores de energia.

A viabilidade quanto a implantação tornou-se evidente porque a comunidade acadêmica ainda direciona de maneira inadequada as pilhas e baterias. Tal comunidade, mostrou-se favorável em relação a alocação do PEV na IES onde estudam, o que, já demonstra uma percepção ambiental mais efetiva, embora ainda pratiquem, em determinadas ocasiões, o descarte inadequado.

\section{Referências}

ALMEIDA JÚNIOR, A.R.; GOMES, H.L.R. Gestão Ambiental e interesses corporativos: imagem ambiental ou novas relações com o ambiente? Ambiente \& Sociedade, São Paulo, v. 15, n. 1, 157 - 177, jan/abr. 2012.

BRASIL. Ministério do Meio Ambiente - MMA. Conselho Nacional do Meio Ambiente -CONAMA. Resolução CONAMA n. 257:99, de 30 de junho de 1999. Brasília. Disponível em: <http://www.mma.gov.br/port/conama llegiabre.cfm?codlegi=257>. Acesso em: 09 jul. 2017

BRASIL. Conselho Nacional do Meio Ambiente - CONAMA, Resolução $n^{\circ} 401$, de 4 de novembro de 2008, publicada no DOU no 215, de 5 de novembro de 2008, Seção 1, página 108-109, alterada pela RESOLUÇÃO N 424, de 22 de abril de 2010, Publicada no DOU n. 76, de 23/04/2010, pág. 113. Disponível em: http://www.mma.gov.br/port/conama/legiabre.cfm?codlegi=589. Acesso em: 03 jul. 2017.

BRASIL. Diagnóstico Socioeconômico e Florestal, do município de Paragominas. Belém: Imazon, 2009.

BRASIL. Lei n. 12.305, de 2 de agosto de 2010. Institui a Política Nacional de Resíduos Sólidos: altera a Lei no 9.605, de 12 de fevereiro de 1998; e dá outras providências. Disponível em: <http://www.planalto.gov.br lccivil 03/ Ato2007-2010/2010/Lei/L12305.htm> Acesso em: 09 jul. 2017.

CARVALHO, D.F.; BARATA, A.J.S.S.; ALVES, R. R. Logística reversa de lixo eletrônico nas organizações públicas, Ciência e Natura, Santa Maria, v. 38, n. 32, p.862-872, ago. 2016.

DEMAJOROVIC, J. et al. Logística reversa: como as empresas comunicam o descarte de baterias e celulares? Rae, São Paulo, v. 52, n. 2, p.165 -178, abr. 2012. 
GAUDÊNCIO, H. R. S. et al. Gerenciamento de Resíduos Sólidos: estudo de caso em uma associação de catadores na cidade de Mossoró-RN. Ambiência, Guarapuava, v. 11, n. 3, p. 685-698, dez.2015.

GERBER, D.; PASQUALI, L.; BECHARA, F.C. Gerenciamento de resíduos sólidos domiciliares em áreas urbanas e rurais. Revista Ibero-americana de Ciências Ambientais, Aquidabã, v. 6, n. 1, p.293-306, mai. 2015.

GERHARDT, T.E.; SILVEIRA, D.T. Métodos de pesquisa. Porto Alegre: UFRGS, 2009.

GINDRI, A.C.O.; LHAMBY, A.R.; A Situação da Logística Reversa em alguns Municípios da Campanha e Fronteira Oeste do Rio Grande do Sul/RS. Ciência e Natura, Santa Maria, v. 38, n. 02, p.1005-1017, ago.2016.

HERDIANA, D.S. et al. Policy of extended producer responsibility: case study. International Food Research Journal, Malaysia v.21, n. 2, p. 873-881, jan. 2014.

IBGE. INSTITUTO BRASILEIRO DE GEOGRAFIA E ESTATÍSTICA. População do município de Paragominas. 2016. Disponível em: $<$ http://cod.ibge.gov.br/EMX>. Acesso em: 08 ago. 2016.

KEMERICH, P. D. C. et al. Descarte indevido de pilhas e baterias: a percepção do problema no município de Frederico Westphalen -RS. Rev. Ele. em Gestão, Educação e Tecnologia Ambiental. Santa Maria, v. 8, n. 8, pp. 1680 - 1688, set/dez.2012.

KEMERICH, P.D.C. et al. Impactos ambientais decorrentes da disposição inadequada de lixo eletrônico no solo. Engenharia Ambiental, Espirito Santo do Pinhal, v. 10, n. 2, p.208-219, abr. 2013.

KRIEGER M.G. et al. Direito Ambiental: Terminologia das leis de meio ambiente. Revista de Direito de Ambiental, São Paulo, v.5, n.13, p.100-111, jan. 2010.

LAVEZ, N.; SOUZA, V. M.; LEITE, P.R. O papel da logística reversa no reaproveitamento do "lixo eletrônico" - um estudo no setor de computadores. Revista de Gestão Social e Ambiental, São Paulo, v. 5, n. 1, p.15-32, abr. 2011.

MCKIBBEN, B. American Earth: Environmental insider reveals how a good cause has gone bad. Guilford: The Lyons Press, 2008.

MORETTI, S.L.A.; LIMA, M.C; CRNKOVIC, L.H.; Gestão de resíduos pósconsumo: avaliação do comportamento do consumidor e dos canais reversos do setor de telefonia móvel. Revista de Gestão Social e Ambiental, São Paulo, v. 5, n. 1, p.03-14, abr. 2011.

MUIR, J. The eight wilderness discovery books. London: Diadem Books, 2008

NEVES, L.S.; SANTOS, A.M. . O Descarte de Aparelhos Celulares. Cad. Unisuam Pesqui. Ext., Rio de Janeiro, v. 5, n. 4, p.127-134, nov. 2015.

Revbea, São Paulo, V. 13, № 2: 351-371, 2018. 
NOGUEIRA, D. et al. Pilhas e baterias descarte correto e sua reciclagem. 2011. Disponível em: <http://unifia.edu.br/revista eletronica/revistas/gestao foco/artigos/ano2011/gestao foco Pilhas.pdf>. Acesso em: 26 ago.2017

OLIVEIRA, E.L. et al. Logística reversa: uma análise do descarte de baterias e celulares nos pontos de coleta da Claro em Chapecó - SC. Simpósio Internacional de Gestão de Projetos, 2. 2013. São Paulo. Anais Eletrônicos... São Paulo. Disponível em: <http://repositorio.uninove.br/xmlui/bitstream/handle /123456789/492/605-1089-1-RV\%20LOGISTICA\%20REVERSA\%20UMA\%20 ANALISE\%20DO\%20DESCARTE.pdf?sequence=1>. Acesso em: 20 ago. 2017

OLIVEIRA, M.F. Metodologia científica: manual para a realização de pesquisas em Administração. Goiás: Catalão, 2011.

OLIVEIRA, P.S.; LIMA, H.P. Logística reversa do pós-consumo em empresas na zona sul da capital paulista coletoras de pilhas e baterias. Revista Gestão \& Sustentabilidade Ambiental, Florianópolis, v. 4, n. 2, p.194-208, mar. 2016.

PARÁ (Estado). Secretaria de Estado de Planejamento, Orçamento e Finanças. Estatísticas Municipais. Mesorregião Sudeste Paraense. Paragominas. 2008. Disponível em:<http://www.sepof.pa.gov.br/estatistica/ESTATISTICAS MUNICIPAIS/Mesorr Sudeste/Paragominas/Paragominas.pdf>. Acesso em: 07 ago.2017.

PINTO, A. et al. Diagnóstico Socioeconômico e Florestal do município de Paragominas. Belém: Imazon, 2009.

QUINTANA, J.F.; BENETTI, L.B. Gestão de resíduos eletrônicos: estudo de caso em uma organização militar de São Gabriel/RS, Ciência e Natura, Santa Maria, v. 38, n. 02, p.889-905, mai/ago. 2016.

SOUZA, V.O. Educação Ambiental na efetivação de práticas ecológicas: Um estudo de caso sobre práticas ecológicas e coleta seletiva na universidade estadual da paraíba. Revista Brasileira de Educação Ambiental, São Paulo, v. 9, n. 2, p.364-375, fev.2014.

SZABÓ, A. M. J. Educação Ambiental e Gestão de Resíduos. 3. ed. São Paulo: Rideel, 2010.

THODE FILHO, S. et al. A logística reversa e a Política Nacional de Resíduos Sólidos: desafios para a realidade brasileira. Revista Eletrônica em Gestão, Educação e Tecnologia Ambiental, Santa Maria, v. 19, n. 3, p. 529-538, set/dez. 2015.

TANSKANEN, P. Management and recycling of electronic waste. Acta Materialia, Finland, v.61, p.1001-1011, 2013. 